\title{
INFLUENCE OF PROTAPER FINISHING FILES AND SODIUM HYPOCHLORITE ON CLEANING AND SHAPING OF MANDIBULAR CENTRAL INCISORS - A HISTOLOGICAL ANALYSIS
}

\author{
Flares BARATTO-FILHO ${ }^{1}$, Denise Piotto LEONARDI ${ }^{2}$, João César ZIELAK ${ }^{2}$, José Roberto VANNI ${ }^{3}$, \\ Sandra Maria Alves SAYÃO-MAIA ${ }^{3}$, Manoel D. SOUSA-NETO ${ }^{4}$
}

\author{
1- DDS, PhD, Department of Dentistry, University of Joinville, Joinville, SC, Brazil and Positivo University, Curitiba, PR, Brazil. \\ 2- DDS, PhD, Department of Dentistry, Positivo University, Curitiba, PR, Brazil. \\ 3- DDS, PhD, Department of Dentistry, University of Pernambuco, Recife, PE, Brazil. \\ 4- DDS, PhD, Ribeirão Preto School of Dentistry, University of São Paulo, Ribeirão Preto, SP, Brazil. \\ Corresponding address: Flares Baratto-Filho - Rua Geraldo Lipka, 65 apto 101 - 81200-590 - Curitiba - Paraná - Brazil - Phone: +55 (41) $3317-3406$ \\ - Fax: +55 (41) 3335-2035 - e-mail: fbaratto@uol.com.br
}

Received: April 18, 2008 - Accepted: August 30, 2008

\begin{abstract}
Q

bjective: This study investigated the influence of the last apical instrument of the ProTaper system with and without $2.5 \%$ sodium hypochlorite for cleaning mandibular central incisors. Material and Methods: Thirty two mandibular central incisors were divided into six study groups: Group I - F1 instrument with $2.5 \%$ sodium hypochlorite; Group II - F1 and F2 with $2.5 \%$ sodium hypochlorite; Group III - F1, F2 and F3 with 2.5\% sodium hypochlorite; Group IV - F1 with distilled water; Group V - F1 and F2 with distilled water; Group VI - F1, F2 and F3 with distilled water. The two remaining teeth comprised the negative control group. The specimens were prepared following the principles of the technique suggested by the manufacturer and then submitted to histological preparation and morphometric analysis. Data were analyzed statistically by the Kruskal Wallis test at $1 \%$ significance level. Results: There was statistically significant difference $(\mathrm{p}<0.01)$ between all study groups, except between Groups I and VI. Conclusions: It was concluded that no technique allowed complete cleaning of the root canals. However, the technique of finishing preparation of the apical third with the F3 instrument with $2.5 \%$ sodium hypochlorite irrigation was the most effective.
\end{abstract}

Key words: Cleaning. Rotary instrumentation. Root canal.

\section{INTRODUCTION}

For achievement of success in endodontic therapy, the dental professional should devote equal care to all steps of endodontic treatment ${ }^{1}$. However, one of the greatest concerns of the endodontist is the cleaning, shaping and disinfection of the root canal. According to Schilder ${ }^{16}$, this ideally leads to a tapered shape from the crown to the apex, simulating the original root canal and permitting complete filling of the root canal system.

The internal anatomy of human teeth is complex and variable. A tooth does not present just a single root canal, but rather a complex system of root canals composed of lateral, collateral, recurrent, secondary, accessory, reticular, intracanaliculli canals and multiple foraminal openings.

Therefore, cleaning of root canals is a challenging procedure. This cleaning occurs during the chemomechanical preparation, eliminating irritants such as bacteria and their byproducts, degenerated pulp and contaminated dentin. This process occurs by the mechanical action of the instruments against the main root canal wall, which is limited to the root canal and does not directly reach the entire radicular complex, combined with the chemical action of the irrigating solutions and the physical process of irrigation-aspiration.

The development of nickel-titanium (Ni-Ti) files was a major advance, especially due to their flexibility, which allows their use as manual instruments or with automated systems. Several types of Ni-Ti files are currently available with new characteristics, new designs, changes in standard taper and different file lengths, such as ProTaper system (DentsplyMaillefer), Hero (Micro Mega), K3 (Sybron Endo) and BioRaCe (FKG Dentaire). The ProTaper instruments are a technological innovation of NiTi systems so far since they present variations in taper along the file length, thus allowing creation of two different instruments in one, presenting tapers ranging from 2 to $19 \%$ in the same instrument ${ }^{15}$.

Rotary Ni-Ti instruments have been shown to efficiently create a tapered root canal shape with low risk of canal 
transportation. In addition, it requires less time than the manual technique ${ }^{6}$. However, the cleaning of the root canal system is not always effective ${ }^{2,18}$, especially in flattened root canals or when the canal does not allow the action of the instruments ${ }^{2}$. Therefore, chemical solutions are essential during chemomechanical preparation ${ }^{2}$.

Among the chemical solutions currently used in endodontics, different concentrations of sodium hypochlorite $(\mathrm{NaOCl})$ are the most common and accepted worldwide due to its properties that contribute to effective chemomechanical debridement of the root canal system. $\mathrm{NaOCl}$ acts as a lubricant for instrumentation and can flush loose debris from root canals ${ }^{4}$. $\mathrm{NaOCl}$ promotes cleaning, dissolves both vital and non-vital tissue and has antibacterial action ${ }^{10}$.

The aim of this study was to evaluate the apical cleaning ability of three apical instruments (F1, F2 and F3) of the ProTaper system in mandibular central incisors associated or not with $2.5 \%$ sodium hypochlorite irrigation in order to determine the instrument and its association with an irrigant for root canal cleaning.

\section{MATERIAL AND METHODS}

The sample was composed of 32 human mandibular central incisors extracted due to periodontal disease, measuring on average $21.0 \mathrm{~mm}$ in length and presenting a radiographically confirmed single root canal, as observed on a mesiodistal radiograph with a size $15 \mathrm{~K}$-file. This tooth type was selected because of their known difficulty of cleaning during preparation, due to its usual flattening. The teeth presented fully formed roots and apical foramen with standard diameter of a size $15 \mathrm{~K}$-file, as measured during visual and radiographic examination for exclusion of specimens. The teeth were stored in $0.1 \%$ thymol solution and maintained at $4^{\circ} \mathrm{C}$ before use.

Endodontic access was made and a size $10 \mathrm{~K}$-file (Dentsply/Maillefer, Ballaigues, Switzerland) was introduced in each canal until it appeared at the apical foramen. The working length was established by subtraction of $0.5 \mathrm{~mm}$ from this measurement. The teeth were randomly divided into six groups of 5 teeth each. All teeth were prepared with ProTaper Ni-Ti files (Dentsply/Maillefer). The cervical and middle thirds of all specimens were prepared with SX instruments $(\mathrm{D} 0=0.19 \mathrm{~mm}$, taper 3.5 to $19 \%)$. At the working length ($1 \mathrm{~mm}$ apical root) the $\mathrm{S} 1(\mathrm{D} 0=0.18 \mathrm{~mm}$, taper 2 to $11 \%)$ and $\mathrm{S} 2$ (D0 $=0.20 \mathrm{~mm}$, taper 4 to $11.5 \%$ ) were used, with variation between groups in the last apical instrument employed F1 $(\mathrm{D} 0=0.20 \mathrm{~mm} /$ taper $7 \%$ at the first $\mathrm{mm}), \mathrm{F} 2(\mathrm{D} 0=0.25 \mathrm{~mm} /$ taper $8 \%$ at the first $\mathrm{mm}$ ) or $\mathrm{F} 3$ (D0 $=0.30 \mathrm{~mm} /$ taper $9 \%$ at the first $\mathrm{mm}$ ) with or without $2.5 \%$ sodium hypochlorite: Group I - apical preparation only with F1 instrument with $2.5 \%$ sodium hypochlorite; Group II - F1 and F2 instruments with $2.5 \%$ sodium hypochlorite; Group III - F1, F2 and F3 instruments with $2.5 \%$ sodium hypochlorite; Group IV - F1 instrument with distilled water; Group V - F1 and F2 instruments with distilled water; Group VI - F1, F2 and F3 instruments with distilled water. A TC 3000 electric motor
(Nouvag, Goldach, Switzerland) was used at $300 \mathrm{rpm}$. Two teeth were used as negative controls, in which no procedure was carried out. Irrigation with $5 \mathrm{~mL}$ of the corresponding irrigating solution was done after each file using the Ultradent Irrigation Kit with navitip \#20 at $5 \mathrm{~mm}$ short of the working length. The solution remained in the canal for $30 \mathrm{~s}$ during instrumentation with each file. For all groups, $10 \mathrm{~mL}$ of the same solution was used for final irrigation.

After preparation, the specimens were submitted to histological processing. The specimens were immersed in $10 \%$ buffered formalin and stored for $12 \mathrm{~h}$ in the same solution until histological processing. The teeth were then washed and decalcified in $10 \%$ glycoacetic acid, the crown was sectioned and discarded, and the root was divided into three sections. The apical $5 \mathrm{~mm}$ were removed, embedded in paraffin and sectioned with a microtome (Leica Microsystems, USA). Fivemicrometer-thick sections were obtained and stained with hematoxylin and eosin. One hundred and fifty transverse sections were obtained for each group. In order to standardize the sample, the first serial transverse section of the apical region was discarded and only the 15 following sections were selected for analysis. The transverse sections were examined with a light microscope $(40 \mathrm{x})$ connected to a computer where the images were recorded using Adobe Premiere, version 5.1 software. A grid was placed over these images to evaluate the total canal area and the area with debris. The percentage of debris in the root canal after chemomechanical preparation was calculated and the non-parametric Kruskal Wallis test was used for statistical analysis at 1\% significance level.

\section{RESULTS}

For Groups I, II and III, which received irrigation with $2.5 \%$ sodium hypochlorite, morphometric analysis showed $17.36 \pm 0.97$ percent debris in root canals prepared only with F1 (Figure 1), $15.61 \pm 0.76$ percent debris in root canals prepared with F1 and F2 (Figure 2) and $10.84 \pm 0.82$ percent debris in root canals prepared with F1, F2 and F3 (Figure 3).

For Groups IV, V and VI, which were irrigated with distilled water, the morphometric analysis showed $28.85 \pm$ 1.31 percent debris in root canals prepared only with F1 (Figure 4), 20.96 \pm 1.51 percent debris in root canals prepared with F1 and F2 (Figure 5), $17.30 \pm 0.81$ percent debris in root canals prepared with F1, F2 and F3 (Figure 6).

For both teeth in the control group, the morphometric analysis showed $70.54 \pm 4.61$ and $68.66 \pm 4.96$ percent debris in root canals.

In a decreasing order, the association of $2.5 \% \mathrm{NaOCl}$ and apical preparation up to instrument $\mathrm{F} 3$ was significantly more efficient in cleaning the root canal system than $2.5 \% \mathrm{NaOCl}$ and instrument F2, distilled water and instrument F3, 2.5\% $\mathrm{NaOCl}$ and instrument $\mathrm{F} 1$, distilled water and $\mathrm{F} 2$ and distilled water and instrument $\mathrm{F} 1(\mathrm{p}<0.01)$. There was no statistically significant difference between the groups of distilled water with instrument $\mathrm{F} 3$ and $2.5 \% \mathrm{NaOCl}$ with instrument $\mathrm{F} 1$ $(\mathrm{p}>0.01)$. 


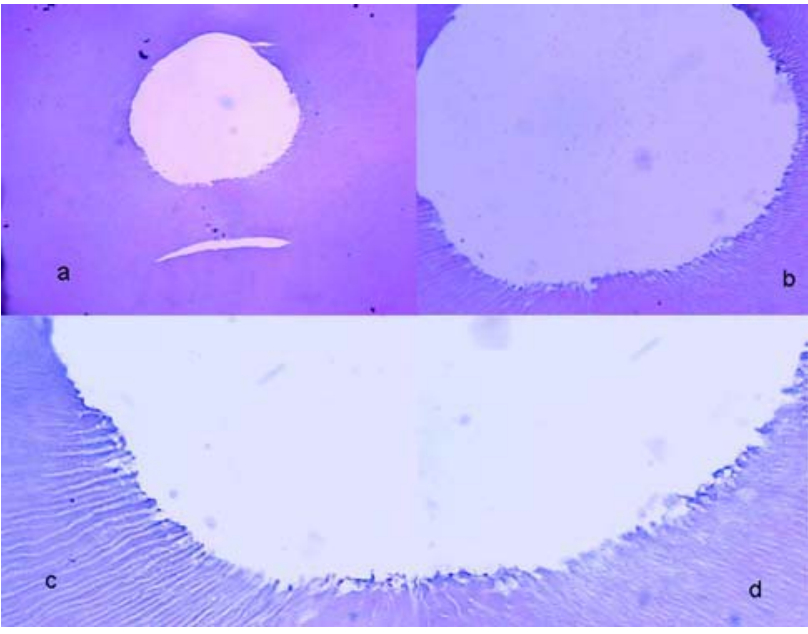

FIGURE 1- Group I- F1 instrument associated with $2.5 \%$ sodium hypochlorite irrigation (HE, a-40x; b-100x; c and d200x)

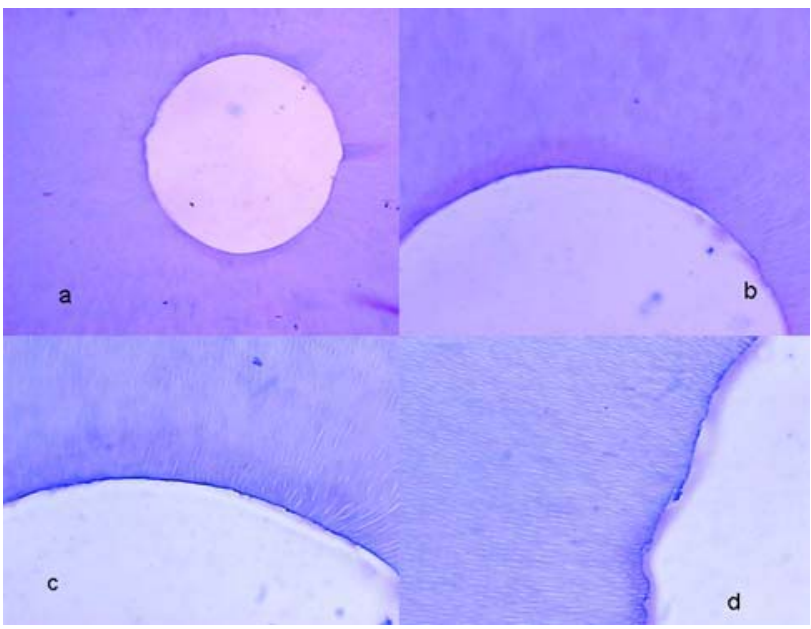

FIGURE 3- Group III- F3 instrument associated with 2.5\% sodium hypochlorite irrigation (HE, a-40x; b-100x; c and d200x)

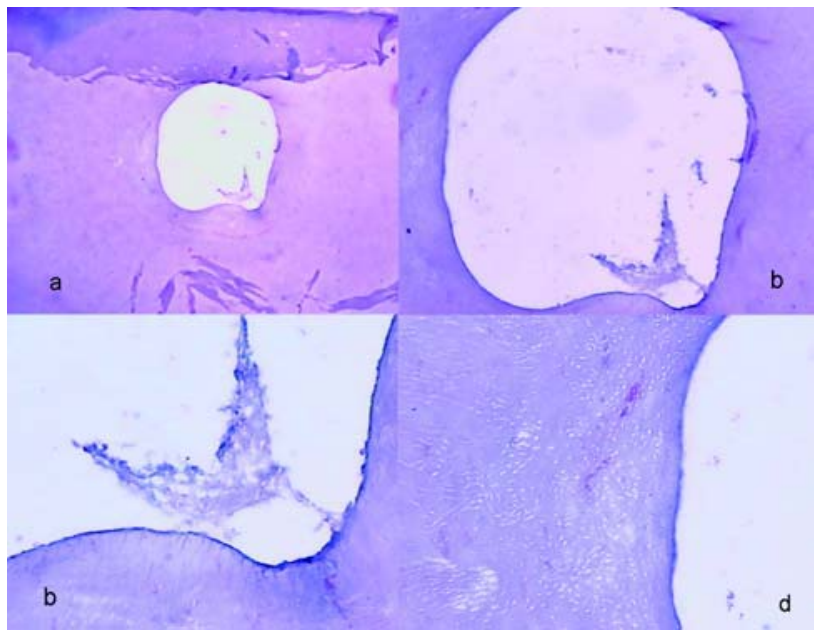

FIGURE 5- Group V- F2 instrument associated with distilled water irrigation (HE, a-40x; b-100x; c and d-200x)

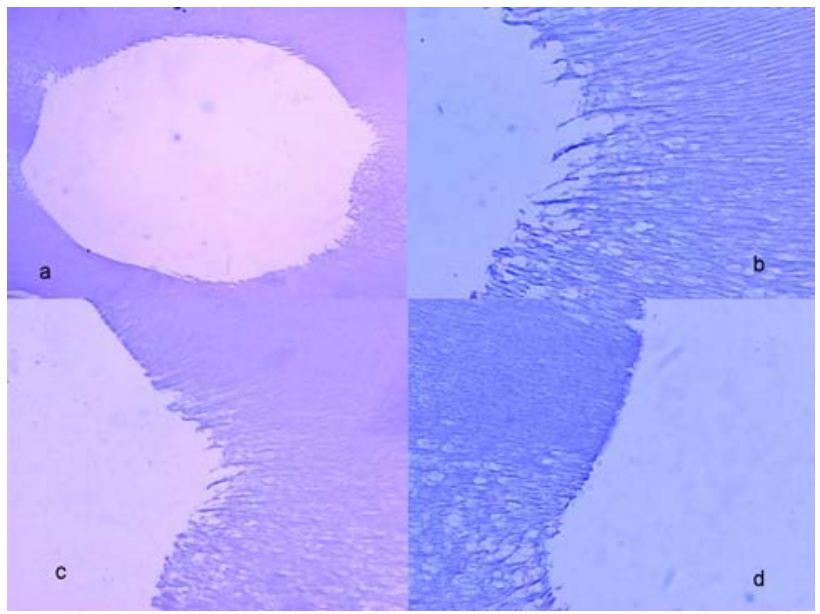

FIGURE 2- Group II- F2 instrument associated with $2.5 \%$ sodium hypochlorite irrigation (HE, a-40x; b, c and d-200x)

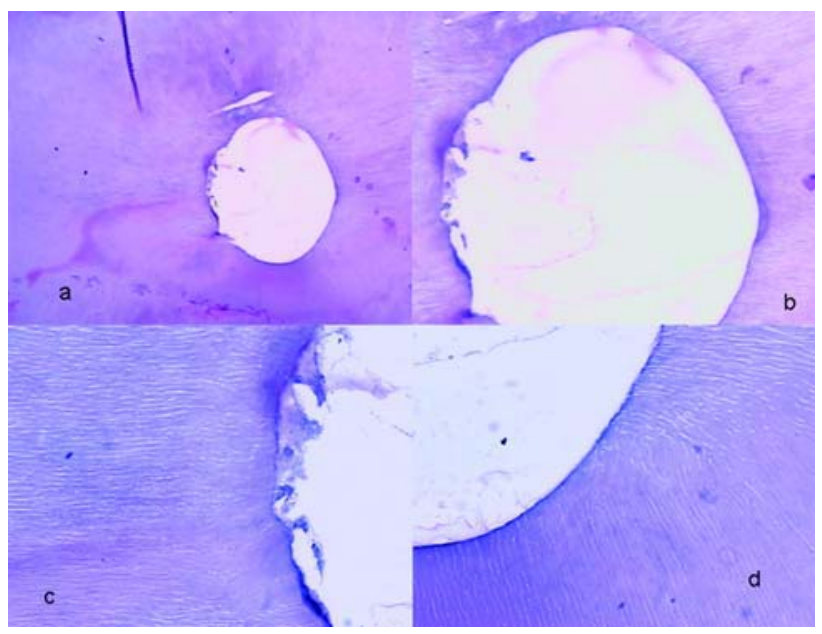

FIGURE 4- Group IV- F1 instrument associated with distilled water irrigation (HE, a-40x; b-100x; c and d-200x)

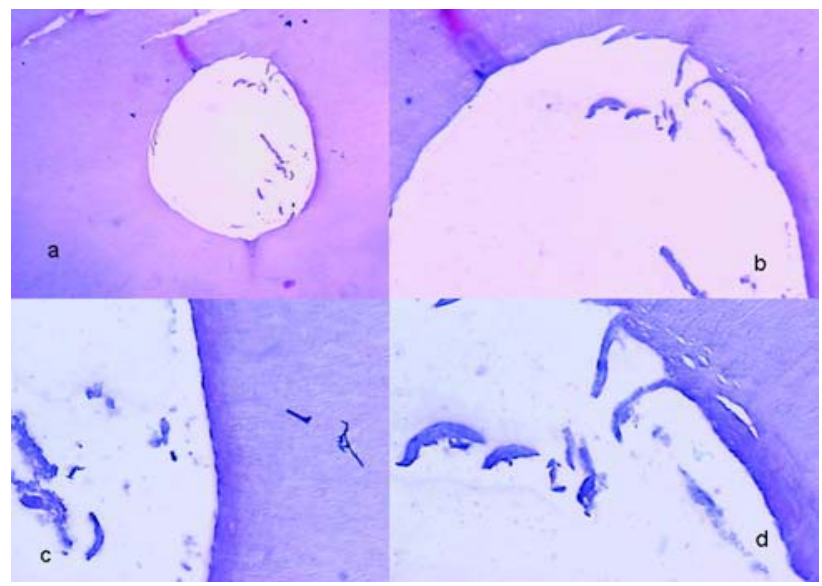

FIGURE 6- Group VI- F3 instrument associated with distilled water irrigation (HE, a-40x; b-100x; c and d-200x) 


\section{DISCUSSION}

Chemomechanical preparation is a fundamental step during endodontic therapy because it combines two interdependent factors, the physical action of the instruments and chemical action of the irrigating solutions. The aim of shaping and cleaning the root canals is to create ideal physiological and morphological conditions for obturation, providing recovery and regeneration of the periapical tissues ${ }^{23}$.

Even though the complete removal of necrotic tissues and debris from the root canal system would be ideal, in most cases only a significant reduction of this content can be achieved. Since the variations in internal anatomy impair the contact between the endodontic file and all internal canal walls of the root canal during preparation, no preparation technique is actually able to provide complete cleaning of the root canal system $^{1,2,3,5,7}$.

Regarding the cleaning of specimens, the results of the present study revealed that the larger the apical instrument of the ProTaper system $(\mathrm{F} 1<\mathrm{F} 2<\mathrm{F} 3)$ employed for preparation, the better the cleaning. Irrigation with $2.5 \%$ sodium hypochlorite clearly produced cleaner root canals than the use of distilled water. Several studies indicate that $5 \%$ sodium hypochlorite demonstrates better cleaning efficacy ${ }^{1,3}$, but there is concern regarding its biocompatibility and potential irritation of vital periapical tissues, especially at high concentrations $\mathrm{s}^{3,17,20,22}$. Therefore, $2.5 \%$ concentration was employed in the present study. There was no statistically significant difference between groups I and VI because the diameter of the F3 instrument is much larger than that of instrument F1. For this reason, the sodium hypochlorite solution was inferior to distilled water in this comparison, being unable to compensate for this difference, since the major cleaning action is achieved by the physical action of the instrument.

None of the finishing files (F1, F2 and F3) was able to act on all internal canal walls, especially at flattened areas and isthmus, which are commonly observed on mandibular central incisors. Kerekes and Tronstad ${ }^{11}$ investigated microscopically the possibility of a minimum shaping diameter for a preparation technique, in order to achieve a round shape during root canal preparation, by analysis of the larger and smaller widths of anterior teeth. In the group of mandibular central incisors, the results revealed $90 \%$ of probability that the last instrument employed for preparation would be a size $70 \mathrm{~K}$-file at $1 \mathrm{~mm}$ from the apex, a size $100 \mathrm{~K}$-file at 2 to 3 $\mathrm{mm}$, and a size $130 \mathrm{~K}$-file at $5 \mathrm{~mm}$. Similarly, Wu, et al. ${ }^{25}$ aimed to establish the apical diameter of human teeth by microscopic analysis of the root canal diameter in mesiodistal and buccolingual directions. In the group of mandibular incisors, the authors observed larger width in buccolingual direction, with similar findings as those of Kerekes and Tronstad, with maximum diameter of 0.80 at $1 \mathrm{~mm}$ from the apex, 0.98 at $2 \mathrm{~mm}$ and 1.80 at $5 \mathrm{~mm}$. Regarding the mesiodistal width, the authors observed maximum diameter of 0.33 at $1 \mathrm{~mm}$ from the apex, 0.51 at $2 \mathrm{~mm}$ and 0.49 at 5 $\mathrm{mm}$. Despite these values, the authors of both studies ${ }^{11,25}$ mentioned the possibility of root perforation when root canal flaring is performed. Therefore, this procedure should be avoided in some cases. These studies ${ }^{11}$ confirm the results obtained in this study, since the last ProTaper instrument corresponds to a size $30 \mathrm{~K}$-file, which represents mild apical flaring in this group of teeth.

The use of rotary systems in general creates round preparations, and thus some internal root canal walls are not instrumented, especially in flattened root canals, ${ }^{1,2,7,9}$. Two types of kinematics may be employed during preparation, namely back-and-forth movements with mild pressure in apical direction ("pecking motion"), or lateral movements without applying pressure on the instrument tip, laterally working on the internal dentinal walls ("brushing"). Theoretically, the lateral movements are less addressed than the apical movements. However, the transverse section, presence of radial land, cutting angle and diameter of each type of instrument may influence this kinematics, which even when correctly applied is not followed by the instrument that should be centered in the canal. This theory might explain the results observed in this study, which presented centralized cutting areas despite "brushing" the instrument against the dentinal walls, achieving better cleaning when some sections presented circular shape compared to excessively flattened shape, in agreement with the results of Peters, et al. ${ }^{14}$.

Another aspect is that the apical widening achieved by the ProTaper finishing instruments may not have been totally effective due to the non-utilization of an anatomical diameter in this system, which is determined by the first instrument posing resistance at the working length, contacting the dentinal walls ${ }^{13}$. According to Pécora, et al. ${ }^{13}$ the establishment of the real anatomical diameter of the root canal is fundamental because it allows safe establishment of the adequate instrument to initiate and adequately widen the root canal, thus assuring more effective elimination of bacteria and debris from the apical region. It is currently known that errors in evaluation of the real root canal diameter may occur, leading to mistaken selection of the first apical instrument and consequently instrumentation, since the feeling of "locking" of the instrument may be assigned to the root canal opening and not to its diameter at the working length ${ }^{21}$. However, in the ProTaper system, widening of the cervical and middle thirds is performed before apical preparation, with the SX, S1 and S2 instruments, which could enhance a more effective establishment of the initial apical anatomical diameter.

According to Ruddle ${ }^{15}$, the ProTaper instruments present a modified design, due to the presence of different tapers along the active tip, which significantly increase their cutting ability; this would be the reason for the need of fewer instruments for proper root canal instrumentation. However, analysis of the results achieved reveals that only these three apical instruments of the ProTaper system are insufficient, at least in this group of teeth ${ }^{11,25}$, to promote real apical widening, with need of using some more instruments at the apical region for this group of teeth.

Recently, Dentsply/Maillefer has introduced the ProTaper Universal with five new instruments ${ }^{26,27}$, three of which (D1, D2 and D3) are primarily indicated for endodontic retreatment (gutta-percha removal) ${ }^{8,19}$, whereas the other two (F4 and F5) 
are indicated for root canal re-preparation in cases of retreatment or even additionally to the original series with a view to increase the apical preparation, since these two instruments present diameter corresponding to sizes 40 and $50 \mathrm{~K}$-file, respectively. Compared to the present results, this might be a solution for obtaining cleaner root canals due to the apical diameter that might be established and reached. However, further studies should be conducted with these instruments to investigate their real action during root canal preparation.

\section{CONCLUSION}

Under the tested conditions, the following can be concluded: 1 . None of the techniques provided completely clean root canals free of debris; 2 . The cleaning ability of the apical instruments of the ProTaper system (F1, F2 and F3) is directly proportional to their diameter; 3 . The $2.5 \%$ sodium hypochlorite solution increases the ability of apical cleaning of the ProTaper system compared to distilled water; 4 . Regarding the cleaning ability of flattened root canals using the ProTaper system according to the proposed methodology, the following sequence was obtained in a decreasing order of cleanliness: - F3 with $2.5 \%$ sodium hypochlorite; - F2 with $2.5 \%$ sodium hypochlorite; - F3 with distilled water and F1 with $2.5 \%$ sodium hypochlorite; - F2 with distilled water; $\mathrm{F} 1$ with distilled water

\section{REFERENCES}

1- Baratto Filho F, Carvalho JR Jr, Fariniuk LF, Sousa-Neto MD, Pécora JD, Cruz Filho AM. Morphometric analysis of the effectiveness of different concentrations of sodium hypochlorite with rotary instrumentation for root canal cleaning. Braz Dent J. 2004;15(1):36-40.

2- Barbizam JVB, Fariniuk LF, Marchesan MA, Pécora JD, Sousa-Neto MD. Effectiveness of manual and rotary instrumentation techniques for cleaning flattened root canals. J Endod. 2002;28(5):365-6.

3- Baumgartner JC, Cuenin PR. Efficacy of several concentrations of sodium hypochlorite for root canal irrigation. J Endod. 1992;18(12):605-12.

4- Baumgartner JC, Mader CL. A scanning electron microscopic evaluation of four root canal irrigation regimes. J Endod. 1987;13(4):147-57.

5- Fariniuk LF, Baratto F Filho, Cruz AM Filho, Sousa-Neto MD. Histologic analysis of the cleaning capacity of mechanical endodontic instruments activated by the endoflash system. J Endod. 2003;29(10):651-4.

6- Fariniuk LF, Baratto F Filho, Guerisoli DMZ, Barbizam JVB, Pécora JD, Sousa-Neto MD. Modeling capacity of ENDOflash files in simulated root canals. Braz Dent J. 2001;12(1):39-42.

7- Gambarini G. Shaping and cleaning the root canal system: a scanning electron microscopy evaluation of a new instrumentation and irrigation technique. J Endod. 1999;25(12):800-3.

8- Gu LS, Ling JQ, Wei X, Huang XY. Efficacy of ProTaper Universal rotary retreatment system for gutta-percha removal from root canals. Int Endod J. 2008;41(4):288-95.
9- Haikel Y, Serfaty R, Wilson P, Speisser JM, Alleman C. Cutting efficiency of nickel-titanium endodontic instruments and the effect of sodium hypochlorite treatment. J Endod. 1998;24(11):736-9.

10- Hand RE, Smith ML, Harrison JW. Analysis of the effect of dilution on the necrotic tissue dissolution property of sodium hypochlorite. J Endod. 1978;4(2):60-4

11- Kerekes K, Tronstad L. Morphometric observations on root canals of human anterior teeth. J Endod. 1977;3(1):24-9.

12- Paque F, Musch U, Hulsmann M. Comparison of root canal preparation using $\mathrm{RaCe}$ and ProTaper rotary $\mathrm{Ni}-\mathrm{Ti}$ instruments. Int Endod J. 2005;38(1):8-16.

13- Pécora JD, Saquy PC, Sousa-Neto MD, Woelfel JB. Root form and canal anatomy of maxillary first premolars. Braz Dent J. 1992;2(2):87-94.

14- Peters OA, Peters CI, Schonenberger K, Barbakow F. ProTaper rotary root canal preparation: effect of canal anatomy on final shape analysed by micro CT. Int Endod J. 2003;36(2):86-92.

15- Ruddle CJ. The Protaper endodontic system: geometries, features and guidelines for use. Dent Today. 2001;20(10):60-7.

16- Schilder H. Cleaning and shaping of the root canal. Dent Clin N Am. 1974;18(2):269-96.

17- Shih M, Marshall J, Rosen S. The bacterial efficiency of sodium hypochlorite as an endodontic irrigant. Oral Surg Oral Med Oral Pathol. 1970;29(4):613-9.

18- Siqueira JF Jr, Araújo MCP, Garcia PF, Fraga RC, Sabóia Dantas CJ. Histological evaluation of effectiveness of five instrumentation techniques for cleaning the apical third of root canals. J Endod. 1997;23(8):499-502.

19- Somma F, Cammarota G, Plotino G, Grande NM, Pameijer CH. The effectiveness of manual and mechanical instrumentation for the retreatment of three different root canal filling materials. J Endod. 2008;34(4):466-9.

20- Spangberg L, Engstrom E, Langeland K. Biologic effects of dental materials. Toxicity and antimicrobial effect of endodontic antiseptics in vitro. Oral Surg Oral Med Oral Pathol. 1973;36(6):856-71.

21- Tan BT, Messer HH. The effect of instrument type and preflaring on apical size determination. Int Endod J. 2002;35(9):752-8.

22- Trepagnier CM, Madden RM, Lazzari EP. Quantitative study of sodium hypochlorite as na in vitro endodontic irrigant. J Endod. 1977;3(5):194-6.

23- Vansan LP, Pécora JD, Costa WF, Maia Campos G. Effects of various irrigating solutions on the cleaning of the root canal with ultrasonic instrumentation. Braz Dent J. 1990;1(1):37-44.

24- Versumer J, Hulsmann M, Schafers F. A comparative study of root canal preparation using ProFile .04 and LightSpeed rotary Ni-Ti instruments. Int Endod J. 2002;35(1):40-7.

25- Wu MK, R'Oris A, Barkis D, Wesselink PR. Prevalence and extent of long canals in the apical third. Oral Surg Oral Med Oral Pathol Oral Radiol Endod. 2000;89(6):739-43.

26- Yared G. Canal preparation using only one Ni-Ti rotary instrument: preliminary observations. Int Endod J. 2008;41(4):339-44.

27- Zang L, Luo HX, Zhou XD, Tan H, Huang DM. The shaping effect of the combination of two rotary nickel-titanium instruments in simulated Sshaped canals. J Endod. 2008;34(4):456-8. 